\title{
Part II-Case Studies for a Synchronous Thermal Instability Operating in Overhung Rotors
}

\author{
A. C. Balbahadur \\ Siemens Westinghouse Power Corporation, Orlando, Florida, USA \\ R. G. Kirk \\ Mechanical Engineering Department, Virginia Tech, Blacksburg, Virginia, USA
}

\begin{abstract}
In Part I, a theoretical model was developed for a synchronous thermal instability that is caused by differential viscous shearing in bearings of overhung rotors. This second part used computer programs, which were based on the theoretical model, to examine various case studies that pertain to this thermal instability. Both plain and tilting pad journal bearing rotors were examined and good agreement was found between the theoretical predictions and the practical results.
\end{abstract}

Keywords Synchronous instability, Thermal bending, Morton Effect, Overhung rotors, Lubricant viscous shearing

\section{INTRODUCTION}

The first part of this article (Balbahadur and Kirk, 2004) describes a theoretical model for the Morton Effect-a synchronous thermal instability that operates mainly in the fluid film bearings of overhung rotors. During this effect, differential viscous shearing (within the bearing lubricant) produces a thermal gradient across the journal. Such a gradient creates a thermal unbalance that can eventually drive the system unstable. It was established that an instability would occur whenever the resultant unbalance $(\mathrm{U})$ on the rotor exceeded a threshold value $\left(\mathrm{U}_{\text {thr }}\right)$.

In this second part of the article, various case studies of rotors with both plain and tilting pad journal bearings will be examined. The data from these case studies will then be compared with results that were generated from the theoretical model.

Received 28 June 2002; accepted 21 November 2002.

Address correspondence to R. G. Kirk, Mechanical Engineering Department, Randolph Hall, Virginia Tech, Blacksburg, VA 24061. E-mail: gokirk@vt.edu

\section{PLAIN JOURNAL BEARING CASE STUDIES}

\section{Keogh and Morton}

In their paper (1994), Keogh and Morton present a theoretical analysis of a symmetric rotor. This rotor, shown in Figure 1, consists of a shaft with a step variation in diameter. The shaft is supported by two identical plain journal bearings and a disk of constant mass is placed, at an overhung position, on either shaft end.

The Keogh and Morton model examined the stability of a complex rotor thermal bend angle. From this complex analysis, they were able to calculate the eigenvalues of the rotor system and determine the corresponding growth factors ( $\sigma=$ real part of eigenvalue). Since the system response depends on $\mathrm{e}^{\sigma \mathrm{t}}$, a positive growth factor would indicate a theoretical instability. The growth factor plot revealed that the critical speed range, in which rotor thermal bending can occur, is between $1,023 \mathrm{rad} / \mathrm{s}$ $(9,769 \mathrm{rpm})$ and $1,086 \mathrm{rad} / \mathrm{s}(10,371 \mathrm{rpm})$.

The current analysis used the data in Table 1 to predict a synchronous thermal instability range from $1,047 \mathrm{rad} / \mathrm{s}(10,001 \mathrm{rpm})$ to $1,206 \mathrm{rad} / \mathrm{s}(11,521 \mathrm{rpm})$ which overlaps with the Keogh and Morton range. In addition, the current model indicates another range of instability after 1,286 rad/s (12,277 rpm). These instability ranges were obtained from the intersection of the resultant unbalance and threshold unbalance curves shown in Figure 2.

The agreement of the current model with the Keogh and Morton data is not excellent, but it is still acceptable. One reason for some discrepancy could be the difficulty encountered in fitting the Keogh and Morton viscosity information with an exponential profile. In some instances (particularly at higher speeds), the viscosity values from the curve fit were greater than the given data. This disagreement could have contributed to higher temperatures and larger thermal unbalances at the elevated speeds. As a result, the predicted instability range would be more prolific than the actual one.

The driving force behind the instability hump in Figure 2 is the high overall mean temperature $(\Delta \mathrm{T})$ between the hot and 


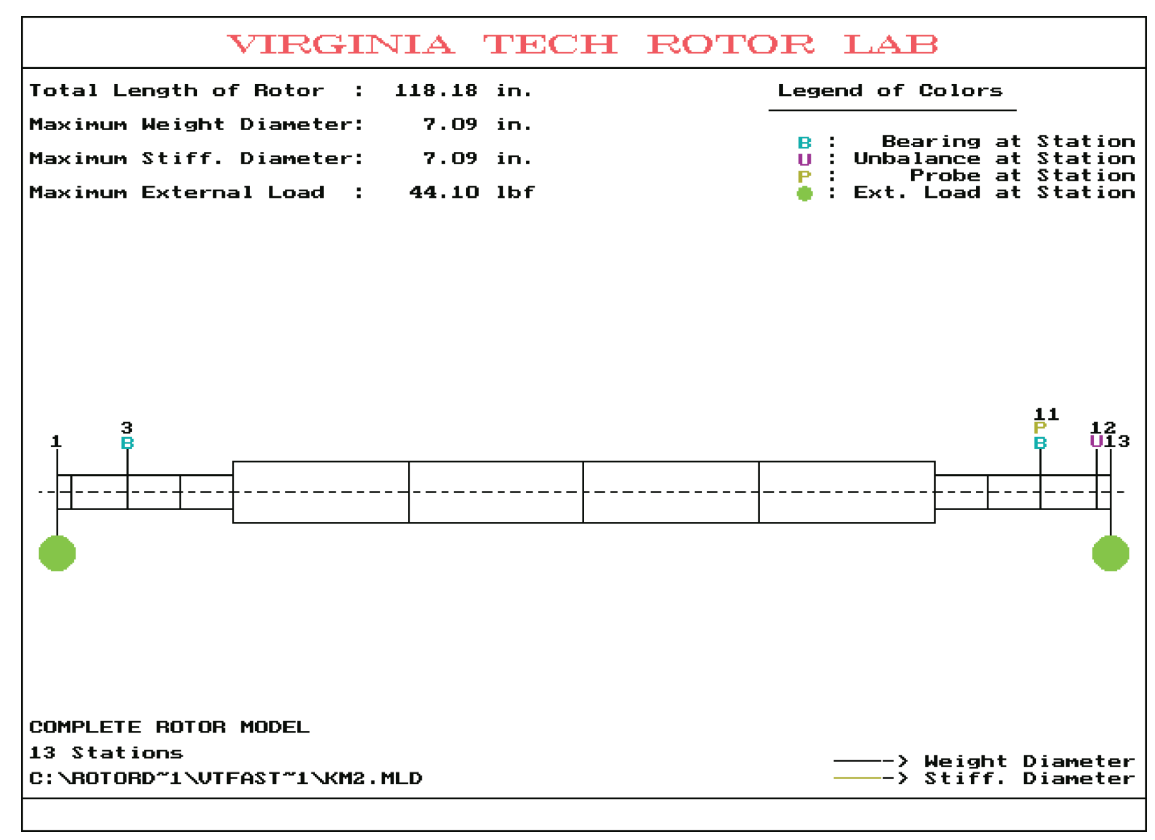

FIGURE 1

VT-FAST model of the Keogh and Morton symmetric rotor.

cold spots. As mentioned above, higher viscosity values could have contributed to these large $\Delta \mathrm{T}$ values. However, the rotor dynamics plays the more important role in generating these high $\Delta$ Ts which lead to greater thermal and resultant unbalances.
An unbalance response analysis revealed that the rotor has a critical speed (4th critical) near 10,500 rpm. This lateral critical speed creates large amplitude orbits in this region. One such orbit (at 10,505 rpm) is illustrated in Figure 3.

TABLE 1

Data for Keogh and Morton Rotor

\begin{tabular}{llll}
\hline Parameter & & \multicolumn{1}{c}{ SI units } & \multicolumn{1}{c}{ EG units } \\
\hline $\begin{array}{l}\text { Lubricant properties } \\
\text { Density }\end{array}$ & $\rho_{\mathrm{l}}$ & $850 \mathrm{~kg} / \mathrm{m}^{3}$ & $0.031 \mathrm{lbm} / \mathrm{in}^{3}$ \\
Specific heat capacity & $\mathrm{c}_{\mathrm{l}}$ & $2000 \mathrm{~J} / \mathrm{kg} /{ }^{\circ} \mathrm{C}$ & $0.478 \mathrm{Btu} / \mathrm{lbm} /{ }^{\circ} \mathrm{F}$ \\
Supply temperature & $\mathrm{T}_{0}$ & $45.0^{\circ} \mathrm{C}$ & $113^{\circ} \mathrm{F}$ \\
Supply viscosity & $\mu_{0}$ & $0.0095 \mathrm{~Pa} \mathrm{~s}$ & $1.38 \mu \mathrm{reyn}$ \\
$\quad$ Thermovisc. coeff. & $\beta$ & $0.029^{\circ} \mathrm{C}^{-1}$ & $0.016^{\circ} \mathrm{F}^{-1}$ \\
Bearing properties & & & \\
Length & $\mathrm{L}$ & $0.035 \mathrm{~m}$ & $1.38 \mathrm{in}$ \\
Radial clearance & $\mathrm{C}_{\mathrm{b}}$ & $1.00 \mathrm{E}-04 \mathrm{~m}$ & $3.94 \mathrm{mils}$ \\
Heat transfer coefficient & $\mathrm{H}$ & $50 \mathrm{~W} / \mathrm{m}^{2} /{ }^{\circ} \mathrm{C}$ & $2.43 \mathrm{e}-5 \mathrm{hp} / \mathrm{in}^{2} /{ }^{\circ} \mathrm{F}$ \\
Bearing load & $\mathrm{W}_{\mathrm{b}}$ & $2500 \mathrm{~N}$ & $562 \mathrm{lbf}$ \\
Journal radius & $\mathrm{R}_{\mathrm{j}}$ & $0.050 \mathrm{~m}$ & $1.97 \mathrm{in}$ \\
$\quad$ Journal C.T.E. & $\alpha$ & $1.10 \mathrm{E}-05^{\circ} \mathrm{C}^{-1}$ & $6.11 \mathrm{E}-06^{\circ} \mathrm{F}^{-1}$ \\
Rotor properties & & & \\
Rotor weight & $\mathrm{W}$ & $5000 \mathrm{~N}$ & $1124 \mathrm{lb}$ \\
Overhung mass & $\mathrm{m}_{\mathrm{d}}$ & $32.3 \mathrm{~kg}$ & $71.3 \mathrm{lb} \mathrm{m}$ \\
Overhang distance & $\mathrm{L}_{\mathrm{d}}$ & $0.16 \mathrm{~m}$ & $6.4 \mathrm{in}$ \\
Max. cont. op. speed & $\omega_{\mathrm{MCOS}}$ & $1047 \mathrm{rad} / \mathrm{s}$ & $10000 \mathrm{rpm}$ \\
Initial mech. unbalance & $\mathrm{U}_{\mathrm{m}}$ & $4.54 \mathrm{e}-4 \mathrm{~kg} \mathrm{~m}$ & $0.63 \mathrm{oz} \mathrm{in}$ \\
\hline
\end{tabular}




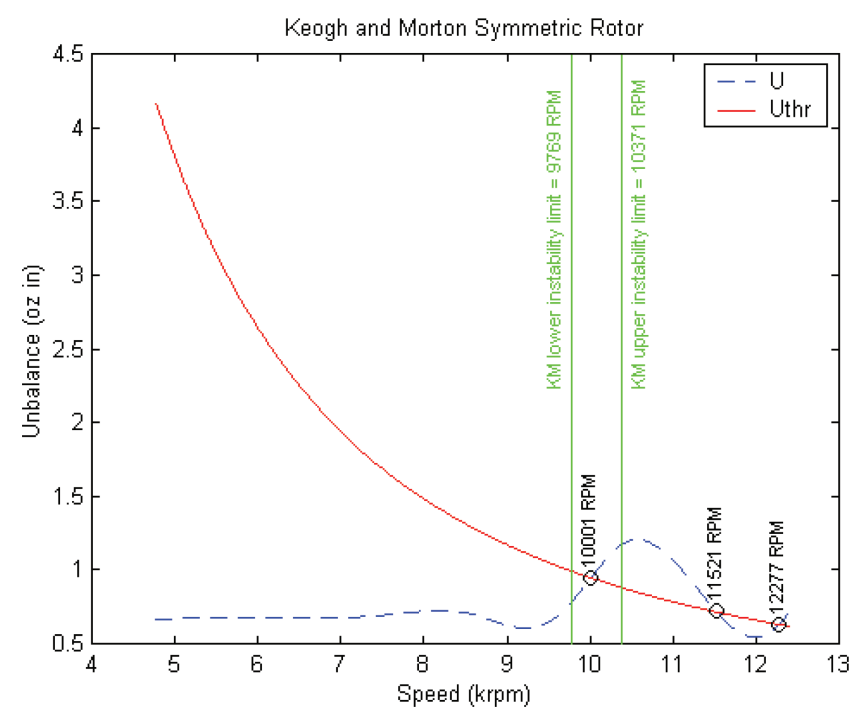

FIGURE 2

Unbalance curves from current analysis of Keogh and Morton rotor.

The lower left and the upper right corners of this orbit show that, in these regions, the rotor is running very close to the radial bearing clearance, $\mathrm{C}_{\mathrm{b}}$. This configuration implies that the film thickness at the hot spot $(\mathrm{x})$ would be very low, while the diametrically opposite cold spot (o) would experience higher film thickness values. Since a lower film thickness is associated with higher viscous dissipation and higher temperatures, a strong thermal gradient will develop across the journal. Such a gradient will cause the $\Delta \mathrm{T}$ value to be high and promote a thermal instability.

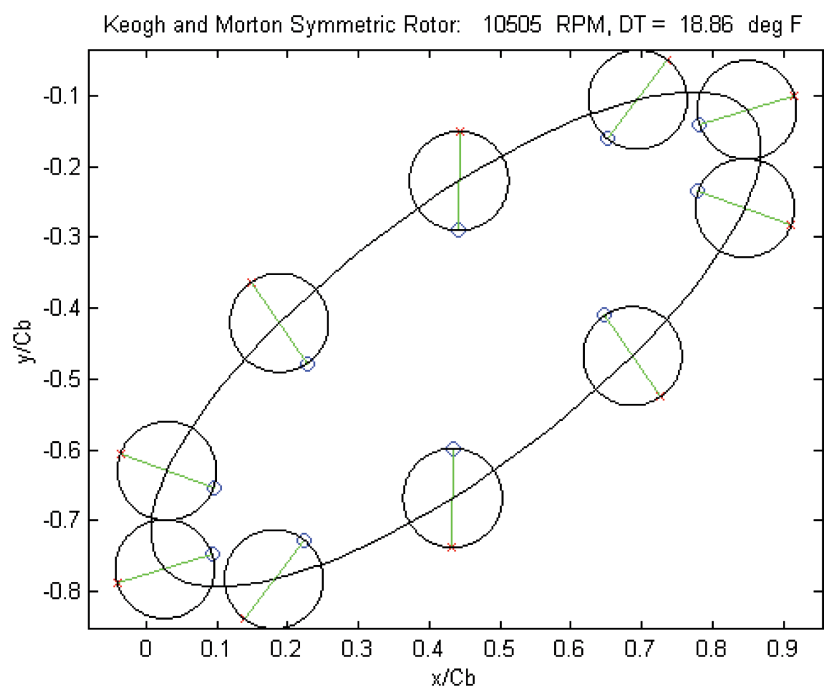

FIGURE 3

Synchronous orbit of the Keogh and Morton rotor at $10,505 \mathrm{rpm}$.

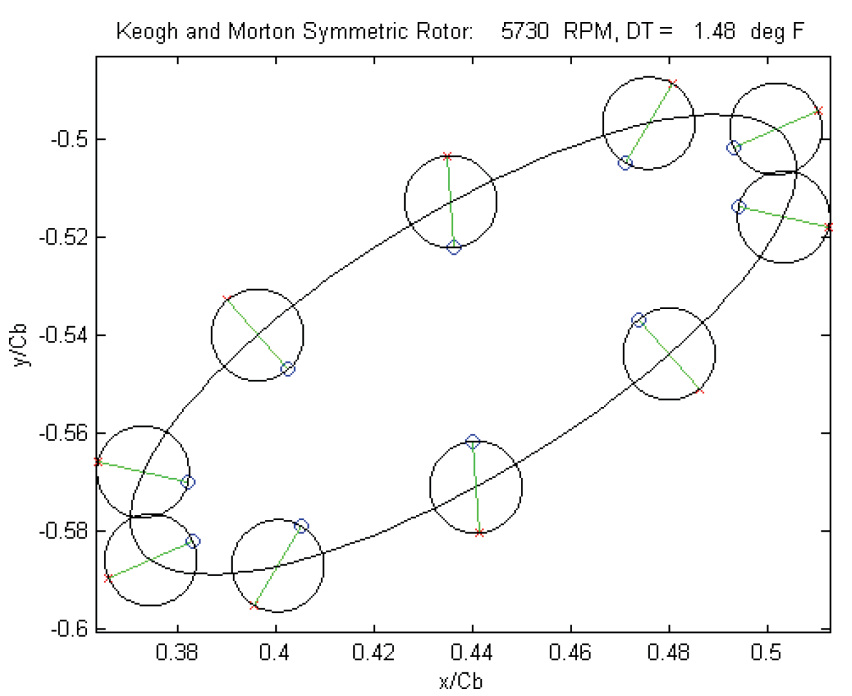

FIGURE 4

Synchronous orbit of the Keogh and Morton rotor at 5,730 rpm.

On the other hand, lower amplitude orbits (see Figure 4), which are further away from the critical speed, keep the rotor away from the clearance circle and are less likely to be associated with high $\Delta \mathrm{T}$ values. Hence, the orbit shown in Figure 4 would not give rise to a thermal bending instability. The lower speed of the 5,730 rpm orbit also reduces the amount of viscous dissipation and this further stabilizes this orbit relative to the $10,505 \mathrm{rpm}$ one.

\section{Faulkner, Strong, and Kirk}

Faulkner, Strong, and Kirk (1997) did an experimental study of a large turbocharger which is shown in Figure 5. The turbocharger had a centrifugal compressor impeller at one end and a radial inflow turbine disk at the other end. This machine was supported by 23 -axial-groove journal bearings which consist of a plain journal bearing with 3 small grooves cut along the bearing length. For simplicity, this type of bearing will be approximated as a plain journal bearing. Other relevant information on the turbine end of this turbocharger is shown in Table 2.

If the heat transfer coefficient is not known (as is the case with the turbocharger bearings), a default value can be calculated by using the following formula:

$$
\mathrm{H}=(0.5)(25.5)(\omega \mathrm{Rj})^{0.7}\left(\mu_{0}\right)^{-0.2}(2 \pi \mathrm{Rj})^{-0.4}
$$

Equation (1) is based on an expression that was derived for tilting pad journal bearings (Ettles, 1992).

During operation, it was observed that the turbocharger became unstable near 9,900 rpm. Faulkner, Strong, and Kirk initially thought that the instability was due to the turbine wheel becoming loose at the high operation speeds. However, a careful inspection of the turbine wheel position, before and after operation, indicated that the wheel did not move while the 


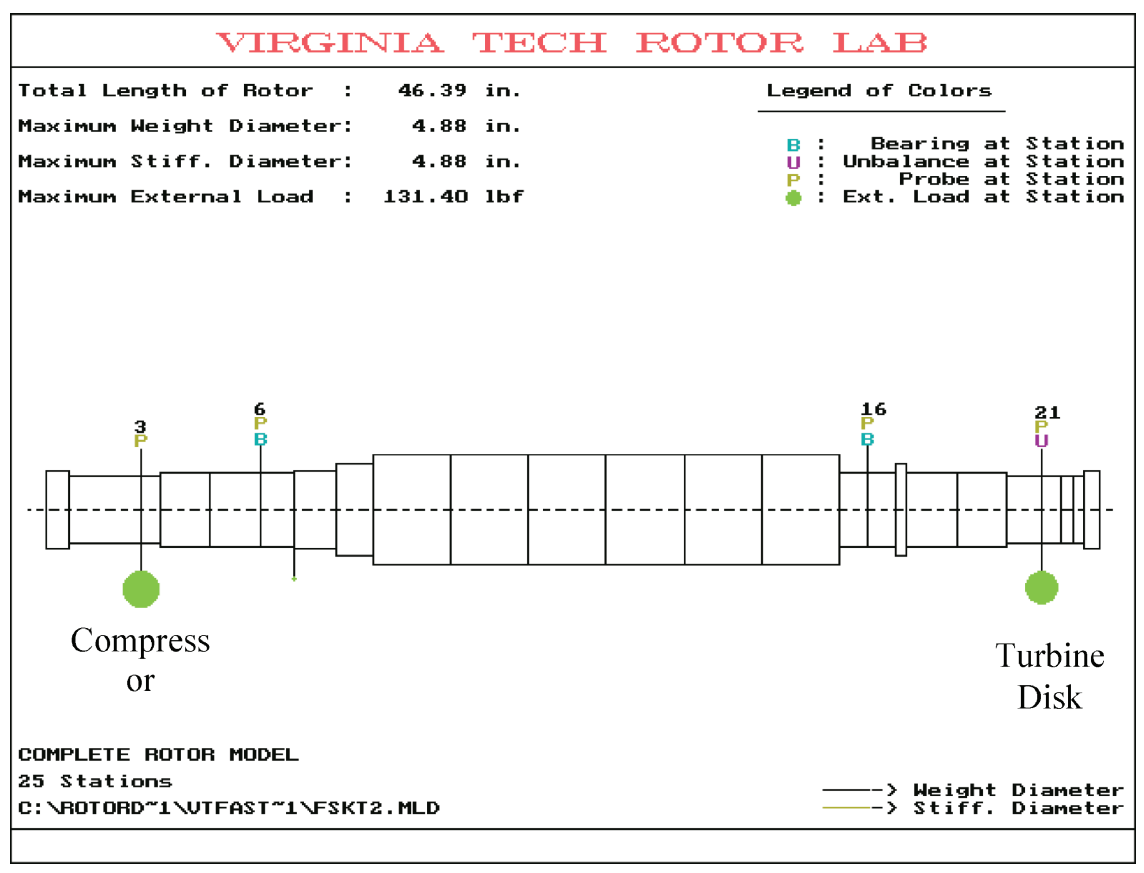

FIGURE 5

VT-FAST model of the turbocharger studied by Faulkner et al. (1997).

turbocharger was running. Furthermore, a damped critical speed analysis failed to justify the existence of a lateral critical speed near $9,900 \mathrm{rpm}$. It was finally concluded that the source of the instability was the thermal bowing of the rotor shaft near the turbine end of the turbocharger.
After using the current thermal instability model to analyze the turbocharger, it was found that the thermal instability was predicted to occur around 1,009 rad/s $(9,640 \mathrm{rpm})$ near the turbine end of the turbocharger (Figure 6). Unlike the Keogh and Morton case, the turbocharger does not encounter criticals with

TABLE 2

Data for Turbine End of Faulkner, Strong, and Kirk Turbocharger

\begin{tabular}{llll}
\hline Parameter & & \multicolumn{1}{c}{ SI units } & \multicolumn{1}{c}{ EG units } \\
\hline $\begin{array}{l}\text { Lubricant properties } \\
\text { Density }\end{array}$ & $\rho_{1}$ & $850 \mathrm{~kg} / \mathrm{m}^{3}$ & $0.031 \mathrm{lbm} / \mathrm{in}^{3}$ \\
Specific heat capacity & $\mathrm{c}_{1}$ & $2000 \mathrm{~J} / \mathrm{kg} /{ }^{\circ} \mathrm{C}$ & $0.478 \mathrm{Btu} / \mathrm{lbm} /{ }^{\circ} \mathrm{F}$ \\
Supply temperature & $\mathrm{T}_{0}$ & $87.8^{\circ} \mathrm{C}$ & $190^{\circ} \mathrm{F}$ \\
Supply viscosity & $\mu_{0}$ & $0.0066 \mathrm{~Pa} \mathrm{~s}$ & $0.952 \mu \mathrm{reyn}$ \\
$\quad$ Thermovisc. coeff. & $\beta$ & $0.031^{\circ} \mathrm{C}^{-1}$ & $0.017^{\circ} \mathrm{F}^{-1}$ \\
Bearing properties & & & \\
Length & $\mathrm{L}$ & $0.057 \mathrm{~m}$ & $2.24 \mathrm{in}$ \\
Radial clearance & $\mathrm{C}_{\mathrm{b}}$ & $7.11 \mathrm{e}-5 \mathrm{~m}$ & $2.8 \mathrm{mils}$ \\
Heat transfer coefficient & $\mathrm{H}$ & Default W/m $/ \mathrm{m}^{2} \mathrm{C}$ & Default hp/in $/{ }^{\circ} \mathrm{F}$ \\
Bearing load & $\mathrm{W}_{\mathrm{b}}$ & $916 \mathrm{~N}$ & $206 \mathrm{bf}$ \\
Journal radius & $\mathrm{R}_{\mathrm{j}}$ & $0.041 \mathrm{~m}$ & $1.63 \mathrm{in}$ \\
$\quad$ Journal C.T.E & $\alpha$ & $1.10 \mathrm{E}-05^{\circ} \mathrm{C}^{-1}$ & $6.11 \mathrm{E}-06^{\circ} \mathrm{F}^{-1}$ \\
Rotor properties & & & \\
Rotor weight & $\mathrm{W}$ & $1877 \mathrm{~N}$ & $422 \mathrm{lb}$ \\
Overhung mass & $\mathrm{m}_{\mathrm{d}}$ & $61.7 \mathrm{~kg}$ & $136 \mathrm{lb} \mathrm{m}$ \\
Overhang distance & $\mathrm{L}_{\mathrm{d}}$ & $0.20 \mathrm{~m}$ & $7.71 \mathrm{in}$ \\
Max. cont. op. speed & $\omega_{\mathrm{MCOS}}$ & $1047 \mathrm{rad} / \mathrm{s}$ & $10000 \mathrm{rpm}$ \\
Initial mech. unbalance & $\mathrm{U}_{\mathrm{m}}$ & $1.73 \mathrm{e}-4 \mathrm{~kg} \mathrm{~m}$ & $0.24 \mathrm{oz} \mathrm{in}$ \\
\hline
\end{tabular}




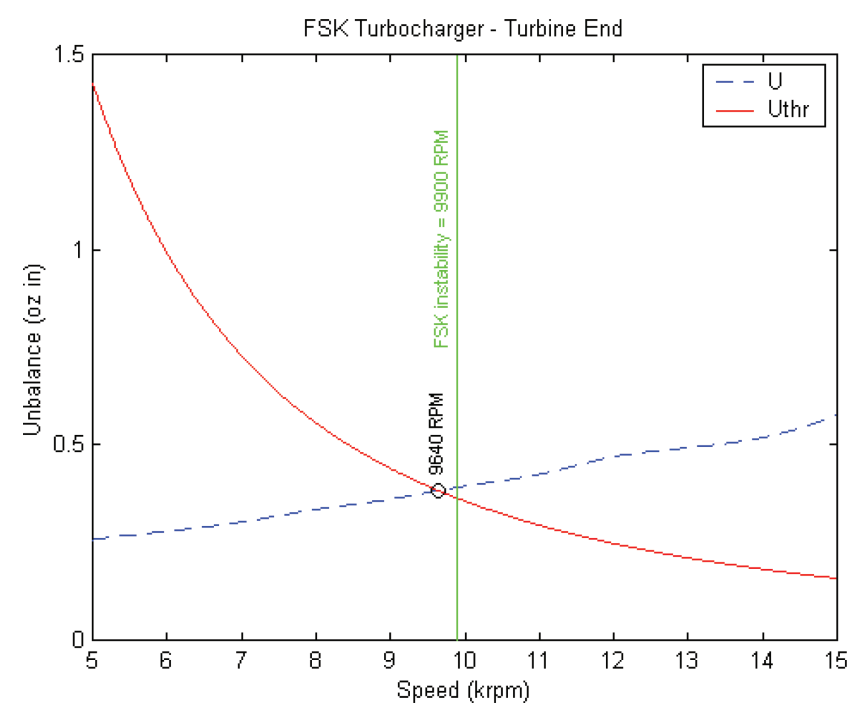

FIGURE 6

Unbalance curves from current analysis of turbine end of the turbocharger studied by Faulkner et al. (1997).

low damping in the given speed range. As a result, there are no large amplitude orbits to produce a sudden instability hump. The monotonic increase in $\mathrm{U}$ can be explained by the increase in speed which leads to increased viscous dissipation, higher $\Delta \mathrm{T}$ values, and more incentive for thermal bending. Figures 7 and 8 illustrate this trend of higher speed leading to higher $\Delta \mathrm{T}$ values. The figures also show that the orbits become more centered at higher speeds, i.e., the center of the elliptical orbit approaches the bearing center $\left(\mathrm{x} / \mathrm{C}_{\mathrm{b}}=0, \mathrm{y} / \mathrm{C}_{\mathrm{b}}=0\right)$ as the rotor speed increases. A more centered orbit means that the hot and cold spot experience almost constant film thickness values, and such a configuration causes a relatively steady thermal gradient to

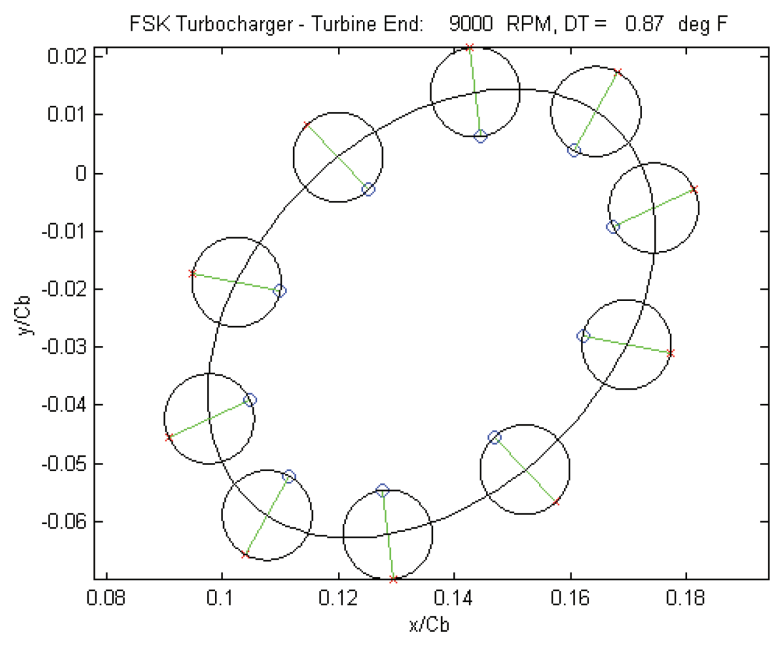

FIGURE 7

Synchronous orbit from turbocharger (turbine end) at $9,000 \mathrm{rpm}$.

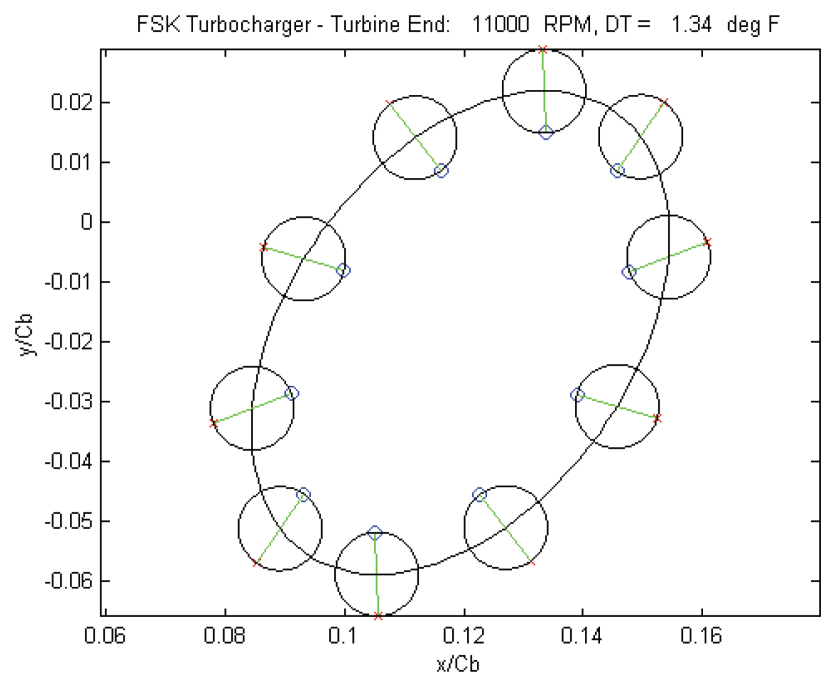

FIGURE 8

Synchronous orbit from turbocharger (turbine end) at $11,000 \mathrm{rpm}$.

develop. In fact, this gradient would be the most steady when the orbit is a circle that is completely centered.

The Keogh and Morton case shows that large amplitude orbits tend to produce high thermal gradients which favor the Morton Effect. If these high gradients are combined with a steady orientation, the worst case scenario for the Morton Effect is achieved; large-amplitude, circular, and centered orbits are the most likely to be associated with the Morton Effect. This scenario can be illustrated by considering Figure 7 and some related orbits. Figure 7 shows a 9,000 rpm synchronous elliptical orbit at the turbine end of the turbocharger. The resultant (U) and threshold $\left(\mathrm{U}_{\mathrm{thr}}\right)$ unbalances for this speed and configuration are $0.36 \mathrm{oz}$ and $0.44 \mathrm{oz} \mathrm{in}$, respectively. If this orbit is forced to center (Figure 9), then the resulting $\Delta \mathrm{T}$ is drastically increased

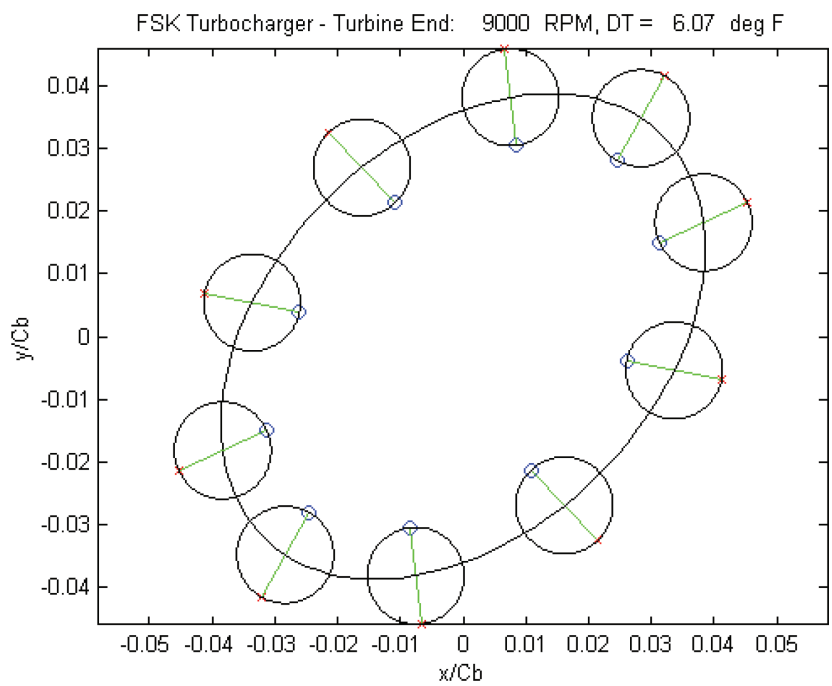

FIGURE 9

Forced 9,000 rpm turbine end orbit: the ellipse is centered. 


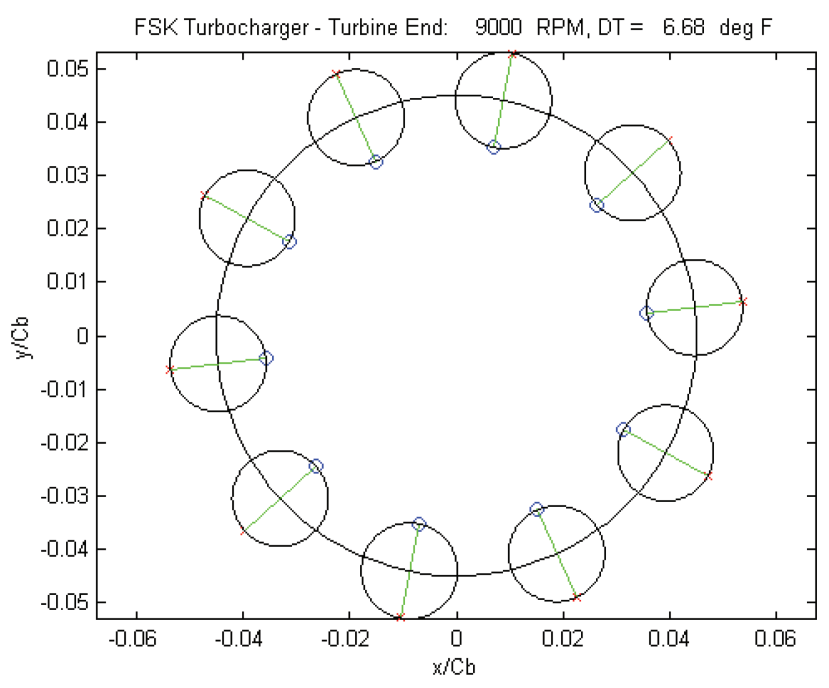

FIGURE 10

Forced 9,000 rpm turbine end orbit: the centered ellipse is changed to a circle.

from $0.87^{\circ} \mathrm{F}$ to $6.07^{\circ} \mathrm{F}$. The resultant unbalance is now $1.09 \mathrm{oz}$ in. which is greater than the threshold value of $0.44 \mathrm{oz}$ in. As a result, the turbocharger is now experiencing the Morton Effect at $9,000 \mathrm{rpm}$.

By changing the semi-major axis of the ellipse in Figure 9 to a radius, the elliptical orbit can be changed into an equivalent circular one (Figure 10). The radius of the circular orbit is equal to the semi-major axis of the ellipse and the $\Delta \mathrm{T}$ value is increased. Now, the value of $U$ is $1.16 \mathrm{oz}$ in.

After increasing the diameter of the circular orbit by a factor of 10 , Figure 11 is obtained. The $\Delta \mathrm{T}$ value has risen to $10.85^{\circ} \mathrm{F}$ and $\mathrm{U}$ is equal to $1.74 \mathrm{oz}$ in. This entire process shows that

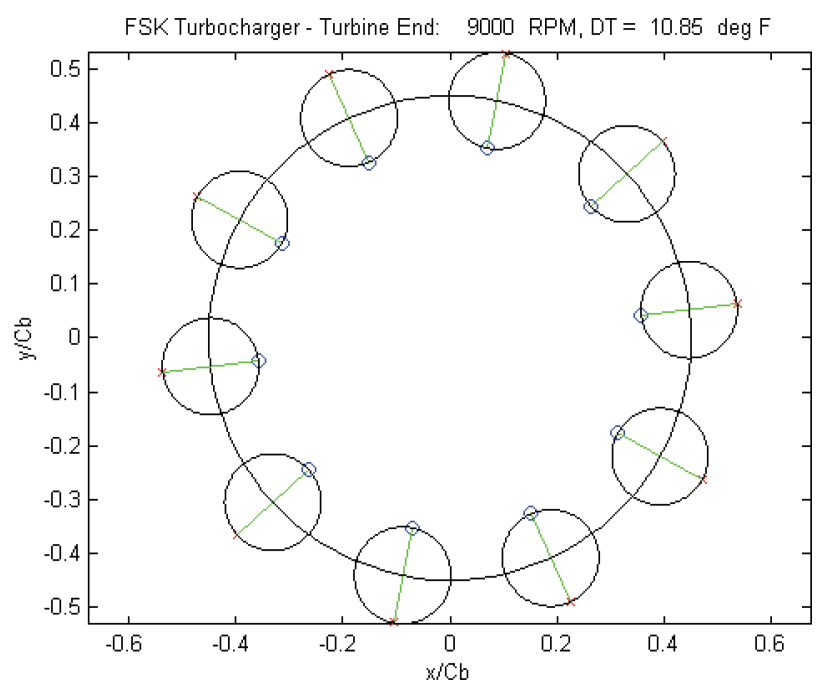

FIGURE 11

Forced 9,000 rpm turbine end orbit: the centered circular orbit is enlarged by a factor of ten. the Morton Effect becomes progressively worse as an orbit is centered, then made to be more circular and finally enlarged.

\section{TILTING PAD JOURNAL BEARING CASE STUDIES}

\section{de Jongh and Morton}

A synchronous vibration problem was encountered by de Jongh and Morton (1994) in their analysis of a LP/IP centrifugal compressor. The compressor was engaged in an off-shore gas-lift operation and its rotor was supported by two 5-pad LOP TPJBs. It was found that it was impossible to attain the maximum continuous operating speed (MCOS) of 11,947 rpm because of unstable vibrations encountered around 11,400 rpm near the non driven end (NDE) bearing. These fast-growing vibrations reached a significant level and thus forced the rig operators to reduce the rotor speed.

Upon examining the rig in a balancing facility it was discovered that the rotor was very sensitive to small unbalances. It was also observed that the vibration problem persisted when the mechanical and labyrinth seals were removed. This precluded the possibility of the Newkirk Effect. However, the hysteresis in the vibration growth and decay seemed to suggest a thermal phenomenon. de Jongh and Morton then built a test rotor with identical dynamic characteristics as the full-sized compressor rotor and measured the temperature difference across the shaft within the bearings. Resulting data confirmed that the vibration problem was caused by thermally induced bending and was therefore a manifestation of the Morton Effect. The final solution to the vibration problem was to reduce the overhang masses.

Using the data in the de Jongh and Morton paper, a VTFAST model of the centrifugal compressor was constructed. The compressor stages and other rotor portions were simplified and modeled as disks, but the dimensions and gyroscopics were essentially the same. Figure 12 shows the resulting model and Table 3 gives the corresponding input data before any modifications were made to attempt to solve the thermal instability problem. The non driven end (NDE) of the centrifugal compressor was then analyzed using the Morton Effect program for the TPJB and the resulting unbalance curves are shown in Figure 13. These curves predict the onset of the instability at $11,508 \mathrm{rpm}$ which is very close to the $11,400 \mathrm{rpm}$ threshold instability value observed by de Jongh and Morton.

The hump around $10,000 \mathrm{rpm}$ in Figure 13 is due to the 3 rd critical speed that provides larger amplitude orbits. These large-amplitude orbits tend to reduce the film thickness near the hot spot and increase the temperature in this region. More incentive for thermal bending is thus obtained and the unbalance level rises. The response diminishes and hot spot film thickness increases after the rotor goes through the critical. As a result, the thermal gradient and the overall unbalance decrease around $11,000 \mathrm{rpm}$. A thermal instability is eventually achieved when the unbalance level rises due to an increase in viscous dissipation at higher speeds. The 4th critical speed around 14,500 rpm also contributes to this trend. 


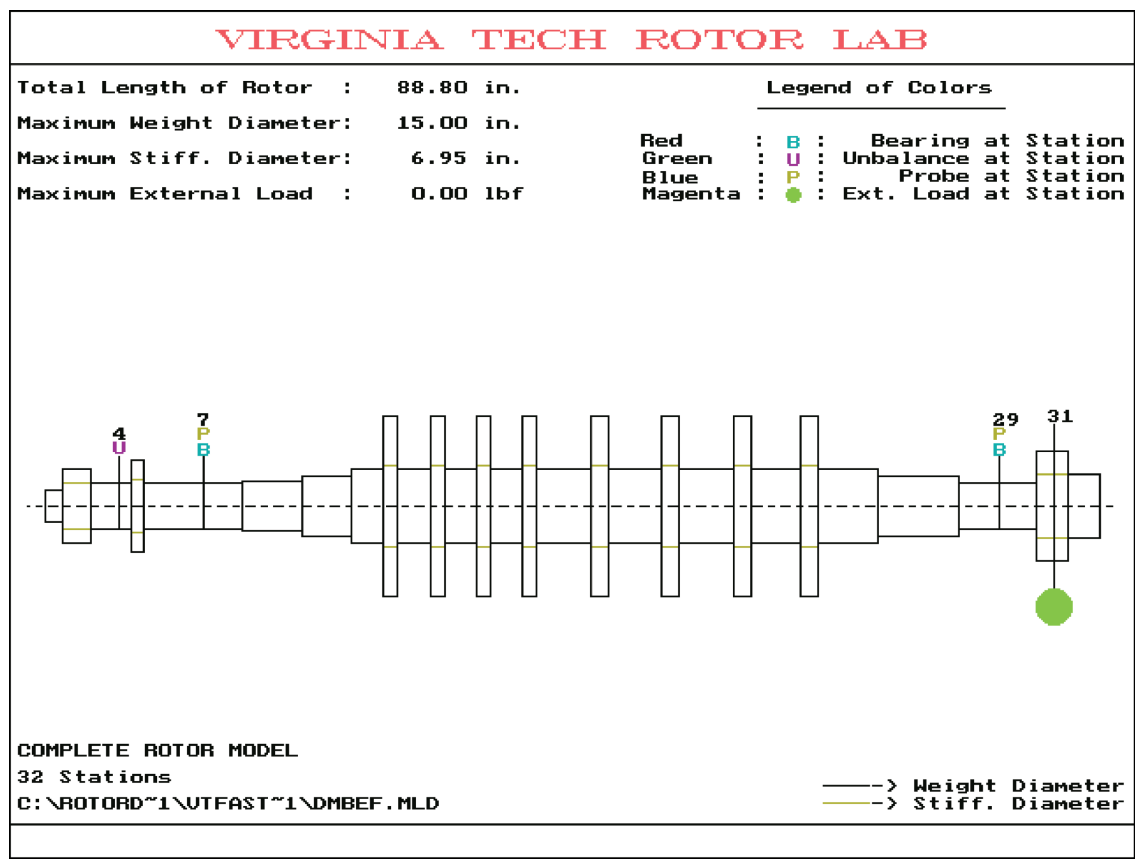

FIGURE 12

VT-FAST model of de Jongh and Morton centrifugal compressor rotor.

The driven-end (DE) of the compressor was also analyzed (Figure 14) and this end seemed to exhibit the Morton Effect at speeds greater than $12,488 \mathrm{rpm}$. This DE instability was not mentioned in the paper by de Jongh and Morton (Year). However, their solution to the thermal instability at $11,400 \mathrm{rpm}$ involved decreasing the overhang masses at both the NDE and the DE.

In order to stabilize the compressor rotor, de Jongh and Morton reduced the NDE overhang mass by $27.6 \mathrm{lb}_{\mathrm{m}}(12.5 \mathrm{~kg})$

TABLE 3

Input Data for de Jongh and Morton Compressor Rotor Before Modifications

\begin{tabular}{|c|c|c|}
\hline Parameter & NDE value & DE value \\
\hline \multicolumn{3}{|l|}{ Pad parameters } \\
\hline L, axial pad or brg length & 1.93 in. $(4.9 \mathrm{~cm})$ & 1.93 in. $(4.9 \mathrm{~cm})$ \\
\hline$t_{p}$, pad thickness & 0.5 in. $(1.27 \mathrm{~cm})$ & 0.5 in. $(1.27 \mathrm{~cm})$ \\
\hline $\mathrm{C}_{\mathrm{p}}$, radial pad clearance & 5.8 mils $(147 \mu \mathrm{m})$ & 5.8 mils $(147 \mu \mathrm{m})$ \\
\hline$\Delta_{\mathrm{p}}$, angular dimension of pad & $56^{\circ}$ & $56^{\circ}$ \\
\hline$\theta_{\mathrm{p}}$, pivot angles of pads (deg) & $54,126,198,270,342$ & $54,126,198,270,342$ \\
\hline $\mathrm{m}$, preload factor & 0.5 & 0.5 \\
\hline$f_{p}$, frac. ang. position of pivot & 0.5 & 0.5 \\
\hline \multicolumn{3}{|l|}{ Journal/bearing parameters } \\
\hline $\mathrm{R}_{\mathrm{j}}$, radius of journal & 1.93 in. $(4.9 \mathrm{~cm})$ & 1.93 in. $(4.9 \mathrm{~cm})$ \\
\hline $\mathrm{W}_{\mathrm{b}}$, bearing load & $488 \mathrm{lb}_{\mathrm{f}}(2172 \mathrm{~N})$ & $506 \mathrm{lb}_{\mathrm{f}}(2250 \mathrm{~N})$ \\
\hline $\mathrm{M}_{\mathrm{d}}$, overhang mass & $59.2 \mathrm{lb}_{\mathrm{m}}(26.9 \mathrm{~kg})$ & $74.0 \mathrm{lb}_{\mathrm{m}}(33.6 \mathrm{~kg})$ \\
\hline $\mathrm{L}_{\mathrm{d}}$, overhang distance & 7.0 in. $(0.18 \mathrm{~m})$ & 4.7 in. $(0.12 \mathrm{~m})$ \\
\hline$\omega_{\mathrm{MCOS}}, \max$. cont. op. spd. & 11947 rpm (1251 r/s) & 11947 rpm (1251 r/s) \\
\hline $\mathrm{U}_{\mathrm{m}}$, initial mech. unbalance & $0.39 \mathrm{oz}$ in. $(0.28 \mathrm{~kg} \mathrm{~mm})$ & $0.39 \mathrm{oz}$ in. $(0.28 \mathrm{~kg} \mathrm{~mm})$ \\
\hline \multicolumn{3}{|l|}{ Lubricant parameters } \\
\hline $\mathrm{P}_{0}$, lubricant supply pressure & 19.1 psi (0.132 MPa) & 19.1 psi (0.132 MPa) \\
\hline $\mathrm{T}_{0}$, lubricant supply temp. & $122^{\circ} \mathrm{F}\left(50^{\circ} \mathrm{C}\right)$ & $122^{\circ} \mathrm{F}\left(50^{\circ} \mathrm{C}\right)$ \\
\hline$\beta$, thermoviscosity index & $0.017 / /^{\circ} \mathrm{F}\left(0.031 /{ }^{\circ} \mathrm{C}\right)$ & $0.017 / /^{\circ} \mathrm{F}\left(0.031 /{ }^{\circ} \mathrm{C}\right)$ \\
\hline$\mu_{0}$, lubricant supply viscosity & $2.94 \mu$ reyn $(20.3 \mathrm{cP})$ & $2.94 \mu$ reyn $(20.3 \mathrm{cP})$ \\
\hline$\rho_{1}$, lubricant density & $0.03 \mathrm{lb}_{\mathrm{m}} / \mathrm{in}^{3}\left(860 \mathrm{~kg} / \mathrm{m}^{3}\right)$ & $0.03 \mathrm{lb} / \mathrm{m}^{3}\left(860 \mathrm{~kg} / \mathrm{m}^{3}\right)$ \\
\hline $\mathrm{c}_{1}$, lubricant $\mathrm{sp}$. heat capacity & $\mathrm{Btu} / \mathrm{lb}_{\mathrm{m}} /{ }^{\circ} \mathrm{F}(2000 \mathrm{~J} / \mathrm{kg} / \mathrm{K})$ & $0.48 \mathrm{Btu} / \mathrm{lb}_{\mathrm{m}} /{ }^{\circ} \mathrm{F}(2000 \mathrm{~J} / \mathrm{kg} / \mathrm{K})$ \\
\hline
\end{tabular}


TABLE 4

Input Data for de Jongh and Morton Compressor Rotor After Modifications

\begin{tabular}{lll}
\hline Parameter & \multicolumn{1}{c}{ NDE value } & \multicolumn{1}{c}{ DE value } \\
\hline Journal/bearing parameters & & \\
$\mathrm{W}_{\mathrm{b}}$, bearing load & $461 \mathrm{lb}_{\mathrm{f}}(2051 \mathrm{~N})$ & $488 \mathrm{lb}_{\mathrm{f}}(2171 \mathrm{~N})$ \\
$\mathrm{M}_{\mathrm{d}}$, overhang mass & $31.6 \mathrm{lb}_{\mathrm{m}}(14.3 \mathrm{~kg})$ & $56.1 \mathrm{lb} \mathrm{m}(25.4 \mathrm{~kg})$ \\
$\mathrm{L}_{\mathrm{d}}$, overhang distance & $4.8 \mathrm{in} .(0.12 \mathrm{~m})$ & $4.0 \mathrm{in} .(0.10 \mathrm{~m})$ \\
$\mathrm{U}_{\mathrm{m}}$, initial mechanical unbalance & $0.37 \mathrm{oz} \mathrm{in.}(0.27 \mathrm{~kg} \mathrm{~mm})$ & $0.37 \mathrm{oz} \mathrm{in.}(0.27 \mathrm{~kg} \mathrm{~mm})$ \\
\hline
\end{tabular}

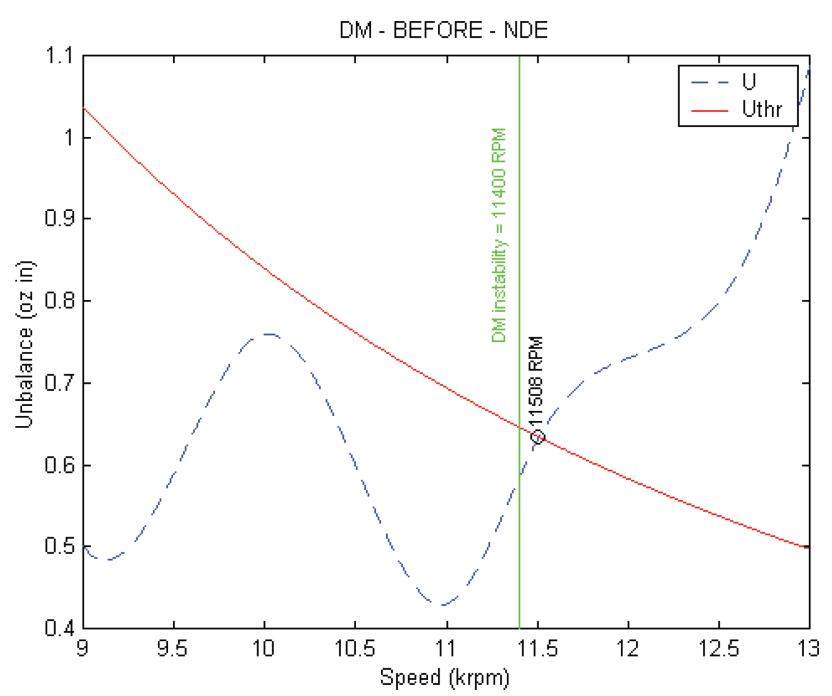

FIGURE 13

Unbalance curves for the non driven end of the de Jongh and Morton compressor (before modifications).

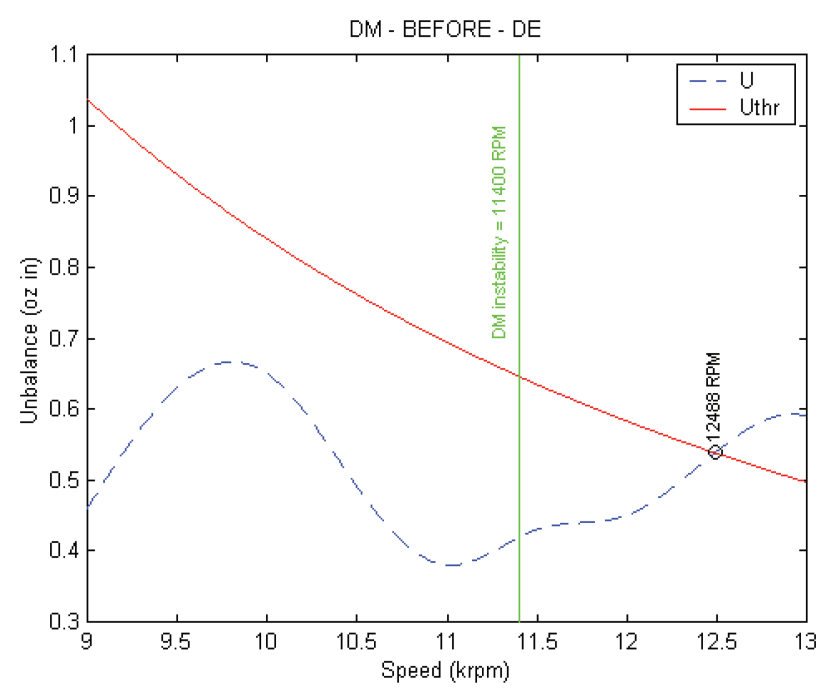

FIGURE 14

Unbalance curves for the driven end of the de Jongh and Morton compressor (before modifications). and decreased the DE overhang mass by $17.9 \mathrm{lb} \mathrm{m}(8.1 \mathrm{~kg})$. These mass reductions were achieved primarily by reducing the density of the overhang components that is they replaced some of the steel components with titanium ones. After these modifications, some of the model input data was changed as indicated in Table 4. The input data not mentioned in Table 4 is the same as that given in Table 3 .

By using the data in Table 4, unbalance curves were obtained for the NDE (Figure 15). These curves show that the thermal instability is not present in the given speed range and the MCOS of 11,947 rpm can be safely achieved. The reduction in the NDE overhang mass stabilizes the rotor system in several ways with respect to the Morton Effect:

1. The lowered mass forces the 4th critical (at around $14,500 \mathrm{rpm}$ ) to a higher speed and thus reduces the influence of this critical on the lower speed orbits. As a result, the resultant unbalance curves $(\mathrm{U})$ are attenuated in magnitude.

2. Decreasing the overhang mass directly reduces $m_{d}$ which, in turn, lowers the thermal unbalance $\left(\mathrm{U}_{t}\right)$ and subsequently decreases U.

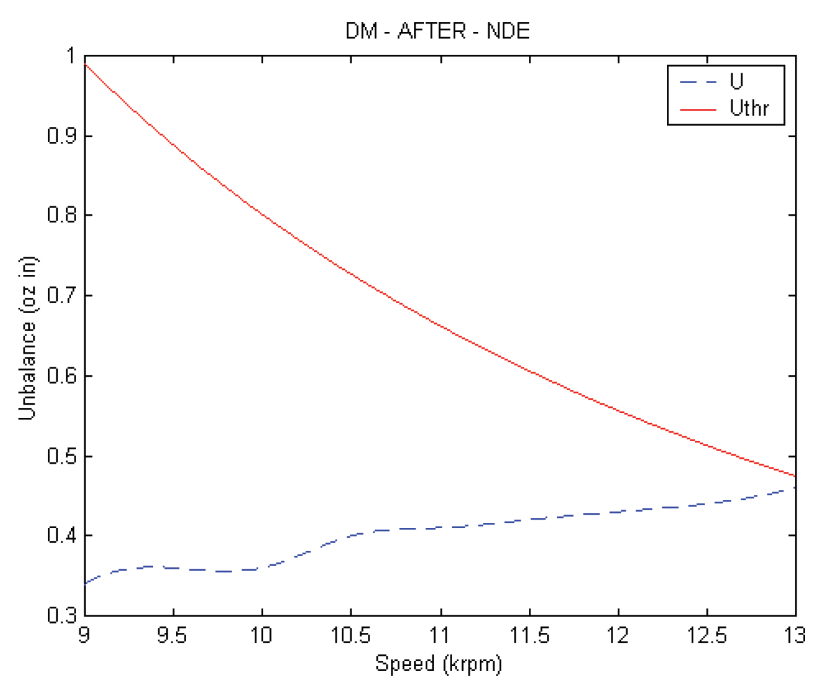

FIGURE 15

Unbalance curves for the non driven end of the de Jongh and Morton compressor (after modifications). 


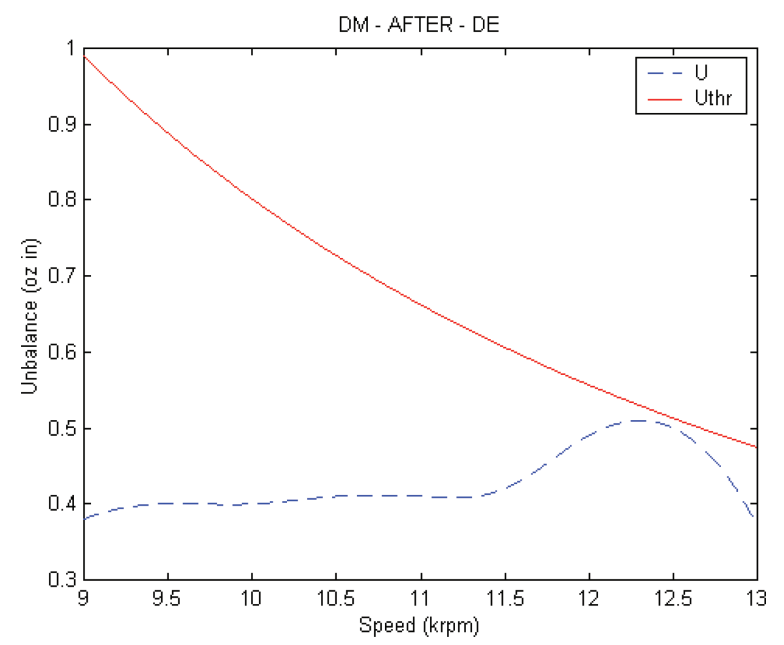

FIGURE 16

Unbalance curves for the driven end of the de Jongh and Morton compressor (after modifications).

3. Since the mass reduction occurs primarily at the ends of the rotor, the center-of-gravity of the overhung mass would be drawn closer to the NDE bearing and the $\mathrm{L}_{\mathrm{d}}$ value (overhang distance) would diminish (compare Tables 3 and 4). This decrease in $L_{d}$ would lower the thermal deflection and thus reduce $U_{t}$. Hence, $U$ would be further reduced and prevented from exceeding the threshold value $\left(\mathrm{U}_{\mathrm{thr}}\right)$.

4. The unbalance peak due to the critical near $10,000 \mathrm{rpm}$ has been significantly attenuated. This attenuation may be partially due to the increase in phase angle between the initial mechanical $\left(\mathrm{U}_{\mathrm{m}}\right)$ and thermal $\left(\mathrm{U}_{\mathrm{t}}\right)$ unbalances. Before modifications, this angle was $31^{\circ}$ near $10,000 \mathrm{rpm}$ but after modifications this angle increased to $61.8^{\circ}$ near $10,500 \mathrm{rpm}$ (near the new position of the attenuated peak). As a result, $U_{m}$ and $\mathrm{U}_{\mathrm{t}}$ are more out of phase which decreases the overall unbalance, $U$. In addition, $U_{t}$ itself is lowered because of the previously discussed reasons.

Figure 16 shows that the mass decrease at the DE also seems to have removed the thermal instability from the operating speed region. Therefore, it appears that there are no Morton Effect possibilities close to the MCOS of $11,947 \mathrm{rpm}(1,251 \mathrm{rad} / \mathrm{s})$. This is in concordance with what de Jongh and Morton observed.

\section{de Jongh and van der Hoeven}

Another example of the Morton Effect operating in rotors supported by TPJBs was provided by de Jongh and van der Hoeven (1998). They analyzed a synchronous instability in two identical pipeline compressors which were being used in a Dutch gas station to transport natural gas. These $584 \mathrm{lb}_{\mathrm{m}}(265 \mathrm{~kg})$ compressors operated between 5,370 and 9,400 rpm and one is schematically shown in Figure 17.

During operation, these compressors exhibited large vibration levels above 7,200 rpm and the machines had to be shut down. Analysis confirmed that these vibrations were synchronous in nature and that there was a hysteresis in the amplitudes. This means that the magnitude of the deceleration vibrations were up to four times the magnitude of the acceleration vibrations over the same speed range. The phase readings from these responses were also erratic. These observations pointed to a

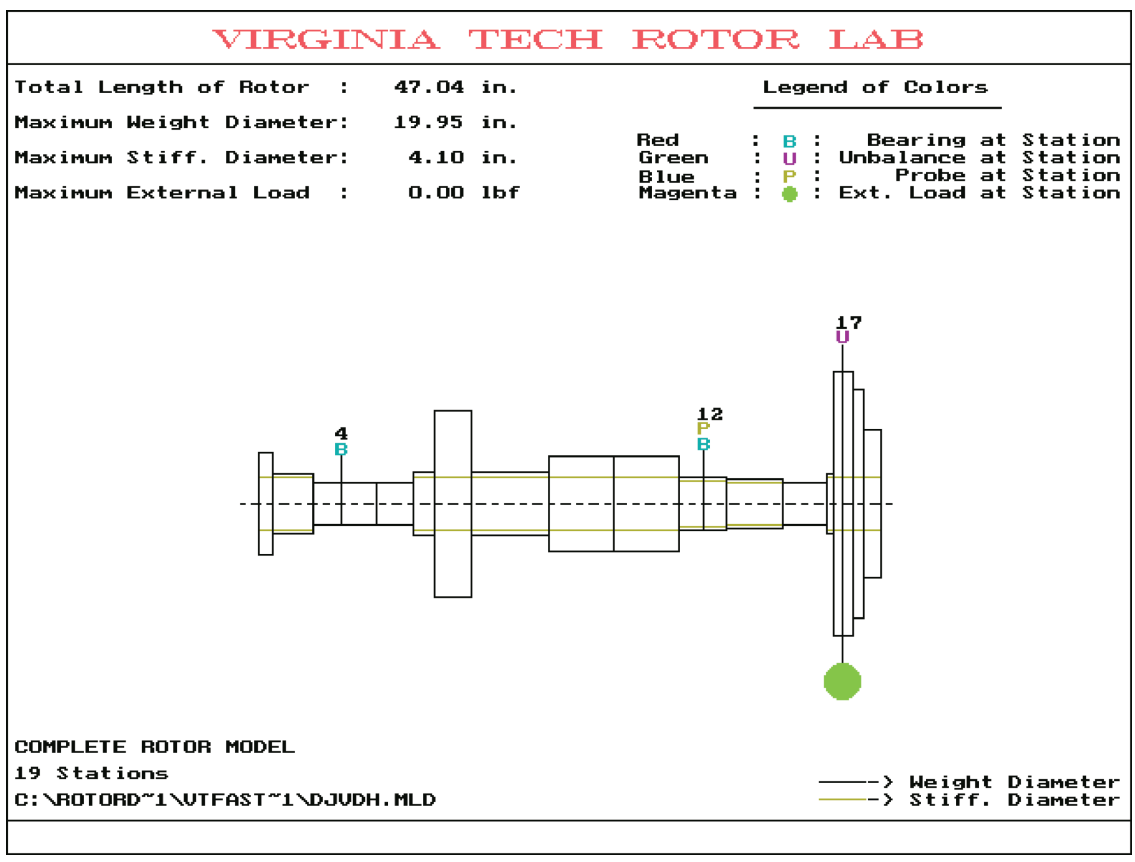

FIGURE 17

VT-FAST model of a compressor analyzed by de Jongh and van der Hoeven. 
thermal instability and the labyrinth seals were checked to determine whether the Newkirk Effect was the cause of the problem. However, these seals did not seem to be initiating a rub and further examination of the shaft did not reveal any scuff marks that are normally associated with shaft rubbing. It was finally concluded that the Morton Effect was the source of the instability and steps were taken to remedy this problem.

The researchers found that increasing the bearing clearance slightly would solve this problem. Increasing the bearing clearance causes a less centered journal orbit which leads to more overall cooling of the hot spot and attenuates the thermal gradient. As a result, the Morton Effect is mitigated and the associated unstable vibration levels would be reduced.

Even though increasing the clearance was a solution to this problem, de Jongh and van der Hoeven decided to adopt a different approach. They found that the minimum required increase in bearing clearance was only $0.03 \%$ which was not a very practical design specification. As a result, they invented a heat sleeve barrier which reduced the temperature gradient across the shaft and decreased the amount of thermal bending caused by the Morton Effect. The current model was applied to the de Jongh and van der Hoeven case and the required input data is given in Table 5.

The overhang mass at driven-end (DE) of the compressors was much smaller than that of the non driven end (NDE) which indicates that the Morton Effect would be more likely to occur at the NDE (as observed by de Jongh and van der Hoeven). As a result, only the NDE will be analyzed for the Morton Effect.

The unbalance curves (Figure 18) predict the onset of thermal instability at 7,070 rpm and this agrees fairly well with the

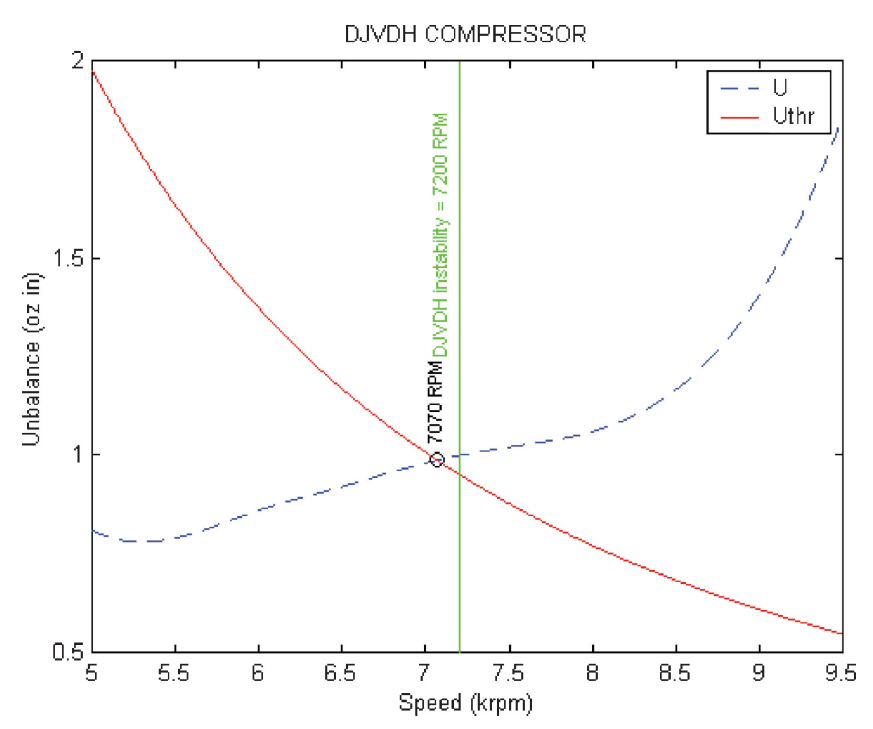

FIGURE 18

Unbalance curves for the non driven end of a compressor analyzed by de Jongh and van der Hoeven (before modifications).
TABLE 5

NDE Data for Compressors Analyzed by de Jongh and van der Hoeven

\begin{tabular}{|c|c|}
\hline Parameter & NDE value \\
\hline \multicolumn{2}{|l|}{ Pad parameters } \\
\hline $\begin{array}{l}\text { L, axial pad or bearing } \\
\text { length }\end{array}$ & 2.0 in. $(5.08 \mathrm{~cm})$ \\
\hline $\mathrm{t}_{\mathrm{p}}$, pad thickness & 0.5 in. $(1.27 \mathrm{~cm})$ \\
\hline $\mathrm{C}_{\mathrm{p}}$, radial pad clearance & 7.0 mils $(178 \mu \mathrm{m})$ \\
\hline $\begin{array}{l}\Delta_{\mathrm{p}}, \text { angular dimension } \\
\text { of pad }\end{array}$ & $56^{\circ}$ \\
\hline$\theta_{\mathrm{p}}$, pivot angles of pads & $54,126,198,270,342^{\circ}$ \\
\hline $\mathrm{m}$, preload factor & 0.5 \\
\hline $\begin{array}{l}\mathrm{f}_{\mathrm{p}}, \text { frac. ang. position of } \\
\text { pivot }\end{array}$ & 0.5 \\
\hline \multicolumn{2}{|l|}{ Journal/bearing parameters } \\
\hline $\mathrm{R}_{\mathrm{j}}$, radius of journal & 2.0 in. $(5.08 \mathrm{~cm})$ \\
\hline $\mathrm{W}_{\mathrm{b}}$, bearing load & $490 \mathrm{lb}_{\mathrm{f}}(2180 \mathrm{~N})$ \\
\hline $\mathrm{M}_{\mathrm{d}}$, overhang mass & $249 \mathrm{lb}_{\mathrm{m}}(113 \mathrm{~kg})$ \\
\hline $\mathrm{L}_{\mathrm{d}}$, overhang distance & 10.5 in. $(0.27 \mathrm{~m})$ \\
\hline$\omega_{\text {MCOS }}, \max$. cont. op. spd. & $9400 \mathrm{rpm}(984 \mathrm{rad} / \mathrm{s})$ \\
\hline $\begin{array}{l}\mathrm{U}_{\mathrm{m}}, \text { initial mechanical } \\
\text { unbalance }\end{array}$ & $0.37 \mathrm{oz}$ in. $(0.27 \mathrm{~kg} \mathrm{~mm})$ \\
\hline \multicolumn{2}{|l|}{ Lubricant parameters } \\
\hline $\begin{array}{l}\mathrm{P}_{0}, \text { lubricant supply } \\
\text { pressure }\end{array}$ & $19.1 \mathrm{psi}(0.132 \mathrm{MPa})$ \\
\hline $\begin{array}{l}\mathrm{T}_{0}, \text { lubricant supply } \\
\text { temperature }\end{array}$ & $122^{\circ} \mathrm{F}\left(50^{\circ} \mathrm{C}\right)$ \\
\hline$\beta$, thermoviscosity index & $0.017 /{ }^{\circ} \mathrm{F}\left(0.031 /{ }^{\circ} \mathrm{C}\right)$ \\
\hline $\begin{array}{l}\mu_{0}, \text { lubricant supply } \\
\text { viscosity }\end{array}$ & $2.94 \mu \operatorname{reyn}(20.3 \mathrm{cP})$ \\
\hline$\rho_{1}$, lubricant density & $0.03 \mathrm{lb}_{\mathrm{m}} / \mathrm{in}^{3}\left(860 \mathrm{~kg} / \mathrm{m}^{3}\right)$ \\
\hline $\begin{array}{l}\mathrm{c}_{1}, \text { lubricant } \mathrm{sp} . \text { heat } \\
\text { capacity }\end{array}$ & $0.48 \mathrm{Btu} / \mathrm{lb}_{\mathrm{m}} /{ }^{\circ} \mathrm{F}(2000 \mathrm{~J} / \mathrm{kg} / \mathrm{K})$ \\
\hline
\end{tabular}

7,200 rpm value recorded by de Jongh and van der Hoeven. Increasing temperature rise due to enhanced viscous dissipation at higher speeds is primarily responsible for the shape of the unbalance curve. Critical speeds also seem to influence the unbalance curve, e.g., around 5,000 and 9,500 rpm.

de Jongh and van der Hoeven solved this thermal instability by installing a heat sleeve barrier around the shaft portion within the bearing. This barrier trapped a layer of air close to the shaft and insulated it from the hot lubricant. As a result, there was minimal heat transfer to the shaft and the thermal gradient across the journal was reduced by about $85 \%$. If this reduction in thermal gradient is included in the current model, the following curves will be obtained. According to Figure 19, the model predicts that the compressor would be stabilized if the heat sleeve barrier were used. This statement agrees with the experimental observations of de Jongh and van der Hoeven. 


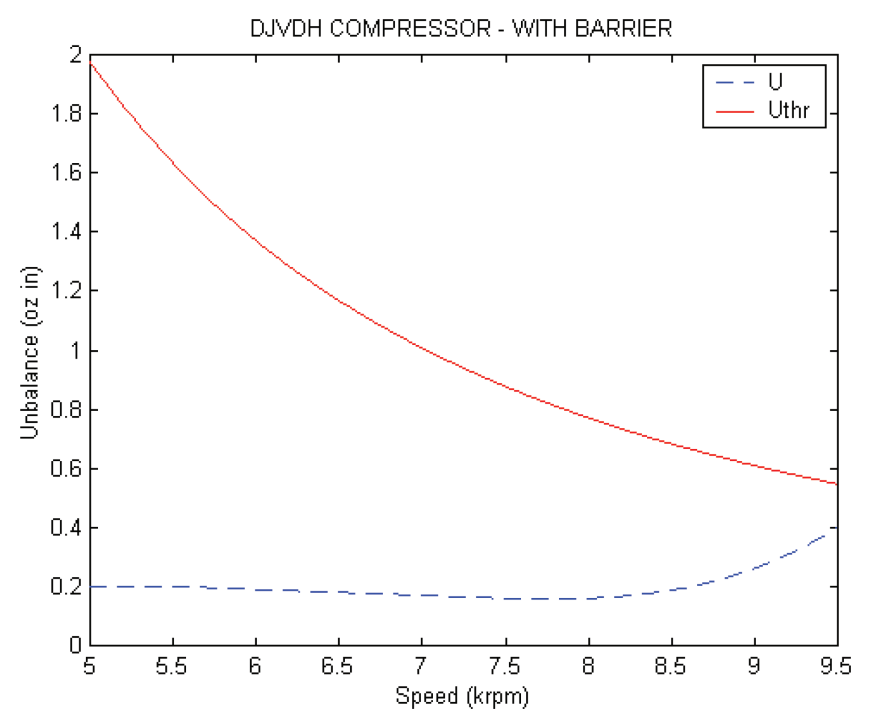

FIGURE 19

Unbalance curves for the non driven end of a compressor (with heat sleeve barrier) analyzed by de Jongh and van der Hoeven.

\section{CONCLUSIONS}

These case studies show that the theoretical model for the synchronous thermal instability (known as the Morton Effect) agrees well with the practical observations. This overall concordance applies to rotors that are supported by plain or tilting pad journal bearings. Furthermore, this work indicates that the worst-case scenario for the Morton Effect would be one with a centered, circular, and large amplitude orbit. Decreasing the phase difference between the thermal and mechanical unbalances would also increase the likelihood of this phenomenon.

\section{NOMENCLATURE}

Dimensions: $M=$ mass, $L=$ length, $t=$ time, $T=$ temperature

$\mathrm{c}_{1} \quad$ lubricant specific heat capacity $\left(L^{2} t^{-2} T^{-1}\right)$

$\mathrm{C}_{\mathrm{b}} \quad$ radial bearing clearance $(L)$

$\mathrm{C}_{\mathrm{p}} \quad$ radial pad clearance $(L)$

$\mathrm{f}_{\mathrm{p}} \quad$ fractional angular position of pad pivot

$\mathrm{H} \quad$ heat transfer coefficient $\left(M t^{-3} T^{-1}\right)$
L bearing length $(L)$

$\mathrm{L}_{\mathrm{d}} \quad$ disk overhang length $(L)$

$\mathrm{m}$ preload factor

$\mathrm{m}_{\mathrm{d}} \quad$ mass of overhung disk $(M)$

$\mathrm{P}_{0} \quad$ lubricant supply pressure $\left(M L^{-1} t^{-2}\right)$

$\mathrm{R}_{\mathrm{j}} \quad$ journal radius $(L)$

$\mathrm{t}_{\mathrm{p}} \quad$ Pad thickness

$\mathrm{T}_{0} \quad$ lubricant supply temperature $(T)$

$\mathrm{U}$ resultant unbalance $(M L)$

$\mathrm{U}_{\mathrm{m}} \quad$ mechanical unbalance $(M L)$

$\mathrm{U}_{\mathrm{t}} \quad$ thermal unbalance $(M L)$

$\mathrm{U}_{\text {thr }}$ threshold unbalance $(M L)$

$\mathrm{W}_{\mathrm{b}}$ bearing load $\left(M L t^{-2}\right)$

$\alpha \quad$ journal coefficient of thermal expansion $\left(T^{-1}\right)$

$\beta \quad$ thermoviscosity coefficient $\left(T^{-1}\right)$

$\Delta_{\mathrm{p}} \quad$ angular dimension of pad

$\theta_{\mathrm{p}} \quad$ pivot angle for pad

$\mu_{0} \quad$ lubricant supply viscosity $\left(M L^{-1} t^{-1}\right)$

$\rho_{1} \quad$ lubricant density $\left(M L^{-3}\right)$

$\omega \quad$ angular journal speed $\left(t^{-1}\right)$

\section{REFERENCES}

Balbahadur, A. C., and Kirk, R. G. 2004. Part I-Theoretical model for a synchronous thermal instability operating in overhung rotors. International Journal of Rotating Machinery 10(6):469-475.

de Jongh, F. M., and Morton, P. G. 1994. The synchronous instability of a compressor rotor due to bearing journal differential heating. ASME Paper 94-GT-35.

de Jongh, F. M., and van der Hoeven, P. 1998. Application of a heat barrier sleeve to prevent synchronous rotor instability. Proceedings of the 27th Turbomachinery Symposium, Turbomachinery Laboratory, Texas A\&M University, College Station, Texas.

Ettles, C. M. 1992. The analysis of pivoted pad journal bearing assemblies considering thermoelastic deformation and heat transfer effects. Tribology Transactions 35(1):156-162.

Faulkner, H. B., Strong, W. F., and Kirk, R. G. 1997. Thermally induced synchronous instability of a radial inflow overhung turbine, Part II. Proceedings of ASME Design Engineering Technical Conferences, Sacramento, California, DETC97/VIB-4174.

Keogh, P. S., and Morton, P. G. 1994. The dynamic nature of rotor thermal bending due to unsteady lubricant shearing within a bearing. Proceedings of the Royal Society of London, Series A 445:273-290. 

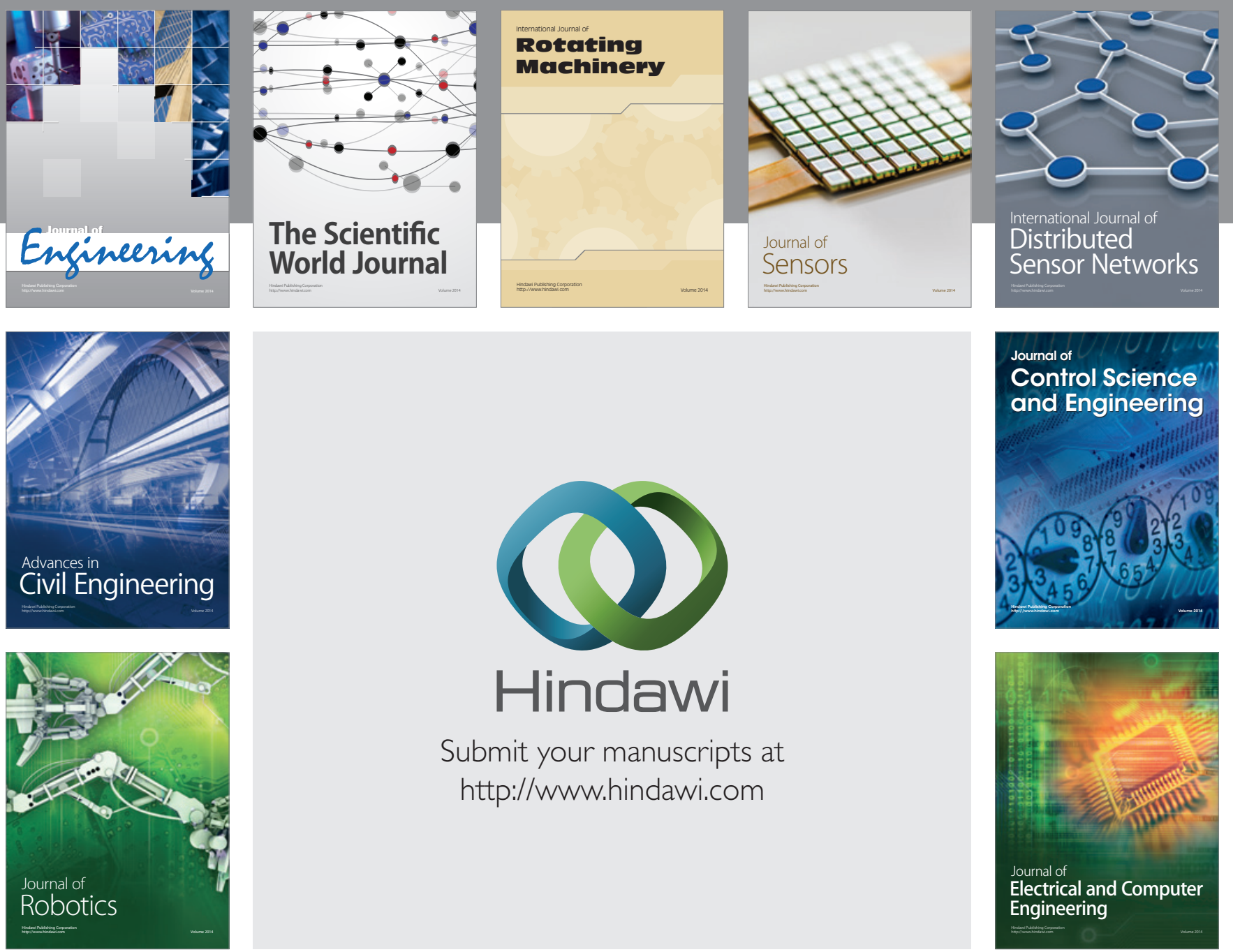

Submit your manuscripts at

http://www.hindawi.com
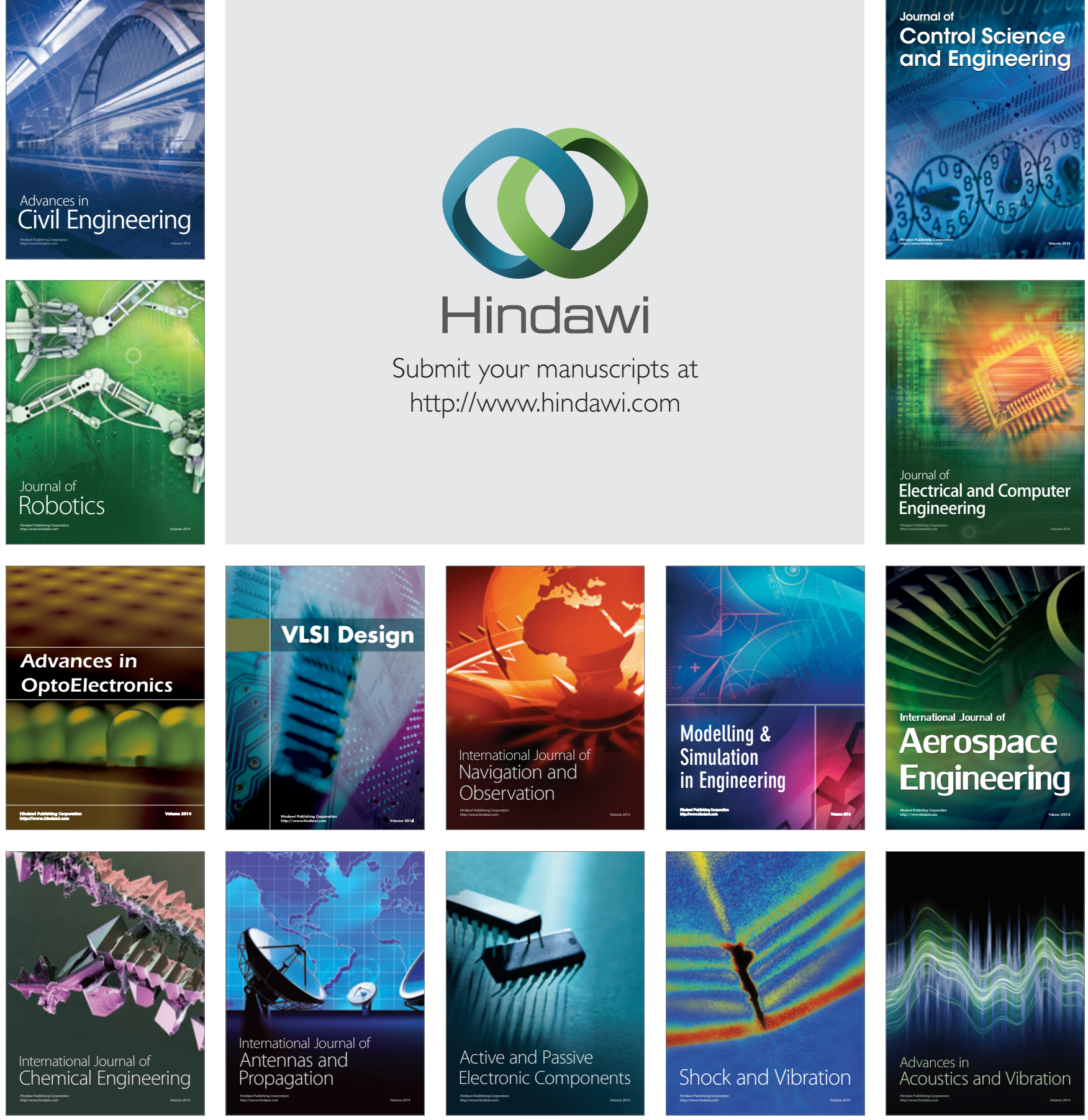